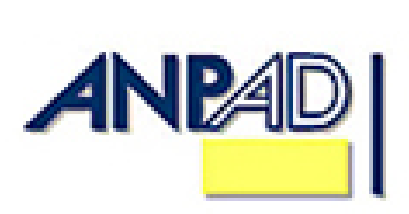

Disponível em

http://www.anpad.org.br/rac

RAC, Curitiba, v. 14, n. 2, art. 6,

pp. 289-309, Mar./Abr. 2010

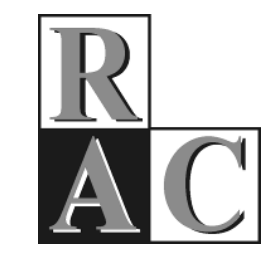

\title{
Importância dos Fatores Não-tecnológicos na Implementação do CPFR
}

\author{
The Importance of Non-technological Factors on CPFR Implementation
}

Mauro Vivaldini *

Doutor em Engenharia de Produção pela UNIMEP. Diretor de Operações Logísticas da Martin Brower do Brasil, Piracicaba/SP, Brasil.

Sílvio R. I. Pires

Doutor em Engenharia de Produção pela USP. Professor do MPA/UNIMEP, Piracicaba/SP, Brasil.

Fernando Bernardi de Souza Doutor em Engenharia Mecânica pela USP. Professor do FE/UNESP, Bauru/SP, Brasil.

* Endereço: Mauro Vivaldini

Universidade Metodista de Piracicaba (UNIMEP), Rodovia do Açúcar, Km 156, Osasco /SP, 13400-911. E-mail: mvivaldini@vianetbr.com.br

Copyright (C) 2010 RAC. Todos os direitos, inclusive de tradução, são reservados. É permitido citar parte de artigos sem autorização prévia desde que seja identificada a fonte. 


\title{
RESUMO
}

De acordo com o Voluntary Interindustry Commerce Standards [VICS], o Collaborative Planning, Forecasting, and Replenishment [CPFR] se baseia na padronização, registro e sincronização de dados eletronicamente, apoiado pela gestão colaborativa existente entre as empresas (VICS, 2004). A partir desta definição, pode-se concluir que existem dois fatores preponderantes na implementação do CPFR: um essencialmente tecnológico e outro não-tecnológico. Nesse contexto, o propósito principal deste estudo é identificar na literatura os chamados fatores não tecnológicos que envolvem o CPFR e analisá-los em situações reais. A importância desses fatores é analisada, então, por meio do estudo de dois casos reais de implementação do CPFR, respectivamente, em uma grande rede de fast food e em um grande distribuidor de alimentos, que operam no Brasil. Os resultados destacam, principalmente, que a previsão da demanda realizada pela empresa coordenadora do CPFR é preponderante sobre o entendimento da demanda por todos os elos da cadeia de suprimentos, que a cultura colaborativa é considerada muito importante no relacionamento ao longo da cadeia (embora não seja determinante para a implementação dos processos) e que o monitoramento das atividades é fundamental para o alinhamento das empresas na gestão do CPFR.

Palavras-chave: gestão da cadeia de suprimentos; logística; CPFR.

\begin{abstract}
According to the Voluntary Interindustry Commerce Standards [VICS], Collaborative Planning, Forecasting, and Replenishment [CPFR] is based on the standardization, registration and electronic synchronization of data, supported by collaborative management among companies (VICS, 2004). Based on this definition, it can be concluded that there are two dominant factors in the implementation of CPFR: one essentially technological and the other non-technological. In this context, the main purpose of this study is to identify the so-called nontechnological factors involved in CPFR reported in the literature and to analyze them in real situations. The importance of these factors is then analyzed through the study of two real cases of CPFR implementation, the first in a large fast food network and the second at a wholesale food distributor operating in Brazil. The main findings indicate that the demand forecast conducted by the company that coordinates CPFR carries the most weight in the understanding of demand by the companies of the whole supply chain, that the collaborative culture is considered a very important factor in the relationships along the chain (albeit not essential to the implementation of processes), and that the monitoring of activities is fundamental in aligning the companies with CPFR management.
\end{abstract}

Key words: supply chain management; logistics; CPFR. 


\section{INTRODUÇÃO}

Desde a publicação em 1998 dos princípios do Collaborative Planning, Forecasting, and Replenishment [CPFR] pelo Voluntary Interindustry Commerce Standards [VICS] (2004), ele vem sendo discutido na literatura na área. Isso tem ocorrido por meio de casos como os da Motorola (Cederlund, Kohli, Sherer, \& Yao, 2007) e da West Marine (Smith, 2006), de estudos teóricos como o de Fliedner (2003) e Attaran e Attaran (2007) e, ultimamente, de estudos que utilizam simulações (Caridi, Cigolini, \& Demarco, 2006; Poler, Hernandez, Mula, \& Lario, 2008; Thron, Nagy, \& Wassan, 2006) na intenção de entender os benefícios da adoção do CPFR ou mesmo de outras ferramentas tecnológicas que contribuam para uma melhor gestão da demanda. Considerando o fato de que o CPFR se baseia na padronização, registro e sincronização de dados eletronicamente, apoiado pela gestão colaborativa existente entre as empresas (VICS, 2004), pode-se concluir que existem dois fatores preponderantes na sua condução: um eminentemente tecnológico e outro não-tecnológico.

Neste contexto, este estudo procura responder ao seguinte: se os fatores não-tecnológicos ligados à gestão colaborativa da Cadeia de Suprimentos [CS] influenciam na prática de um CPFR. Os fatores tecnológicos neste estudo são entendidos como troca de dados e informações eletrônicas. A busca dessa resposta é conduzida primeiramente por meio de uma pesquisa teórica a respeito do CPFR com a intenção de entender, definir e fundamentar proposições a respeito de quais são os fatores nãotecnológicos mais relevantes para a condução de um CPFR. Numa segunda etapa, por meio de um estudo prático de dois casos, é analisada a influência real desses fatores. Por fim, os autores discutem as informações pesquisadas na intenção de contribuir com novas informações para empresas e pesquisadores.

A importância e contribuição deste estudo baseiam-se no fato de ser o CPFR um conceito novo, ainda não consolidado, que carece de mais estudos e definições, e também por analisar o CPFR sob a perspectiva de seus fatores não tecnológicos. Além disso, destaca-se o fato de a pesquisa trabalhar com casos práticos que abordam a sua implementação e gestão, apresentando e discutindo os processos e a experiência de empresas em projetos desta natureza.

\section{REVISÃO SOBRE CPFR}

Considerando a posição definida pelo VICS (2004), que comprador e vendedor, mediante colaboração, trabalham juntos para atender à demanda do cliente, este estudo considera a colaboração entre os agentes da CS e a gestão da demanda como conceitos básicos na condução do CPFR. Também, considerando que a troca de dados, comunicação e a gestão dos inventários se apóiam fundamentalmente na tecnologia da informação, pressupõe-se que esta tecnologia afeta diretamente os resultados obtidos pelo CPFR. Por outro lado, os fatores não tecnológicos, ou seja, os não relacionados à troca de dados e à tecnologia da informação e comunicação [TIC], também influenciam o CPFR. Assim, os tópicos a seguir trazem aspectos relevantes relacionados à Gestão da Demanda, Gestão Colaborativa na CS, CPFR e aos fatores não tecnológicos que o influenciaram.

\section{Gestão da Demanda}

O CPFR, segundo o modelo concebido pelo VICS (2004), tem na sua essência o objetivo de atender a demanda gerada pelo consumidor final. Uma importante premissa é que aperfeiçoando-se os métodos de prever a demanda, pode-se planejar melhor as vendas. A gestão da demanda desempenha o papel de conduzir este trabalho de previsão ao longo da cadeia e seus agentes. Portanto, gestão da demanda, vista como elemento da gestão da CS, é a coordenação do fluxo da demanda através da cadeia de suprimentos e seu mercado (Mentzer \& Moon, 2004). 
Forslund e Jonsson (2007), num estudo sobre a qualidade da previsão de demanda, defendem que a qualidade da previsão realizada pode rapidamente ser prejudicada em função de variações nas especificidades da demanda. Isto reforça a idéia de que a demanda deve ser entendida, analisada e revisada sempre no menor intervalo de tempo possível, para que quanto antes se corrija a previsão. Daí a importância das ferramentas tecnológicas capazes de rapidamente processar informações na CS na gestão da demanda.

Por outro lado, a informação e os dados coletados na CS devem ser bastante acurados, pois esta maior precisão melhora o desempenho de ferramentas como Electronic Data Interchange [EDI], Vendor Managed Inventory [VMI] e CPFR (Sari, 2008). Attaran e Attaran (2007) citam que a melhoria na precisão das previsões é importante fator para práticas colaborativas. As empresas precisam melhorar a previsão e este desafio impulsiona a busca por soluções e métodos de gestão (para coordenação dos agentes) e de tecnologia (para se ter precisão e velocidade).

Para Cassivi (2006), com o uso de novos métodos e ferramentas tecnológicas, atividades como o planejamento, previsão e reposição podem ser administradas de forma mais justas, facilitando a troca e distribuição de informação na CS. Porém cada membro da CS é geralmente forçado a repensar o caminho para alavancar o relacionamento com seus parceiros comerciais, especialmente clientes e supridores.

A gestão colaborativa na CS exige envolvimento dos agentes no planejamento da demanda. Isto só acontece se houver uma gestão de informação e dados em tempo real entre os membros da cadeia (Barratt, 2003). A compreensão desta prática não é simples. Tanto no aspecto global da cadeia quanto no individual, os conflitos e dificuldades são pertinentes ao processo colaborativo, e a coordenação das ações, por meio de um comitê liderado pela empresa que exerce a liderança (governança) da cadeia, pode, então, contribuir para o sucesso da gestão da demanda.

\section{Gestão Colaborativa na Cadeia de Suprimentos}

O momento acadêmico para definição do que venha a ser gestão colaborativa na CS talvez ainda seja prematuro devido à diversidade de idéias e conflitos. Contudo, este estudo adotará a definição de Min et al. (2005) combinada com a de Simatupang, Wright e Sridharan (2002), ou seja, gestão colaborativa acontece quando duas ou mais empresas compartilham responsabilidades para, em comum, dividirem o planejamento, a administração, a execução e os resultados da CS.

Segundo Barratt (2004), ferramentas tecnológicas relacionadas à gestão colaborativa na CS ganharam destaque em meados dos anos 1990 com o surgimento e reconhecimento do CPFR. Antes dele, as empresas utilizavam ferramentas de colaboração, como o Vendor Managed Inventory [VMI], o Continuous Replenishment [CR] e o Continuous Replenishment Programmes [CRP], mas sem a abrangência e a importância que os conceitos advindos do CPFR incorporaram a elas nas práticas colaborativas na gestão da CS.

Autores como Min et al. (2005) e Cox (2004a, 2004b) estudaram a gestão colaborativa na CS independentemente das ferramentas tecnológicas que a apóiam. Para eles, a colaboração é constituída de valores que devem ser incorporados pelas empresas e, se praticados, tendem a favorecer os resultados.

A gestão colaborativa na CS surge da visão de que uma única empresa não obtém sucesso atuando sozinha. Neste sentido, Bowersox, Closs e Stank (2003) defende a formação de parcerias que envolvem trabalho, informação, recursos, riscos e objetivos compartilhados.

A colaboração entre os agentes de uma CS vem constituindo-se em uma meta para as empresas. Este movimento nas CS é apontado em uma pesquisa de Porier e Quinn (2006), segundo os quais, embora esta visão esteja presente entre as empresas, a verdadeira colaboração ainda é um conceito muito difícil de ser aceito, especialmente quanto ao compartilhamento de informações internas com os 
parceiros externos. Mesmo assim, a maioria das empresas reconhece a necessidade de trabalhar em colaboração com seus supridores e clientes ou, pelo menos aparentemente, utilizam este discurso.

Uma das forças trabalhadas pelas empresas têm sido o investimento em ferramentas tecnológicas e métodos que apóiam o relacionamento, como o CPFR. Quanto ao aspecto tecnológico, Kent e Mentzer (2003) complementam que os gestores de CS necessitam entender que: investimento em TIC pode levar a um relacionamento comprometido na CS; que o comprometimento na CS pode levar à eficiência logística; e que não é suficiente simplesmente investir em TIC, uma vez que isso, por si só, não será capaz de manter um bom relacionamento. A posição desses citados autores reforça a importância deste estudo sobre a influência de fatores não tecnológicos no CPFR.

Golic e Mentzer (2006) relatam que os diferentes tipos de relacionamento entre empresas surgem por diferentes situações, sendo que cada relacionamento requer diferentes tipos e graus de investimentos, o que produz resultados divergentes. Já Poler et al. (2008) consideram que, numa rede de empresas, diferentes tipos de colaboração podem estabelecer-se entre cada união dos nós da CS e cada nó poderá ter diferentes comportamentos e tipos de colaboração. Fica evidente, portanto, a dificuldade encontrada pelas empresas para conduzirem o relacionamento na cadeia.

Para Sahay (2003), a visão do processo colaborativo é ter os fornecedores, produtores, distribuidores e clientes alinhados num relacionamento cooperativo, para que se propiciem benefícios à cadeia e a cada agente. Isso significa adotar uma perspectiva externa, em que a decisão das empresas deva considerar não somente o resultado individual, mas de toda a cadeia.

\section{CPFR}

Segundo o manual do VICS (2004), o CPFR é uma prática comercial que combina a inteligência de múltiplos parceiros no planejamento e atendimento da demanda do consumidor. São consideradas quatro atividades colaborativas para melhoria do desempenho na CS:

- Estratégia e planejamento: Estabelecer regras para todos para o relacionamento colaborativo. Determinar o mix, o estágio e os planos de desenvolvimento dos produtos para um dado período.

- Demanda e gestão do abastecimento: Projetar a demanda de venda, assim como garantir que os pedidos sejam expedidos no prazo.

- Execução: Colocar pedidos, preparar e expedir, receber e estocar produtos no varejo, gravar as transações de venda e fazer pagamentos.

- Analises: Monitorar as atividades de planejamento e execução para exceções. Agregar resultados, e calcular o desempenho. Dividir idéias e ajustes de planos para continuamente melhorar os resultados.

Entender e colocar em prática essas quatro atividades é um desafio das organizações e, em função disto, muito se discute a respeito. Nesta linha, autores como Cassivi (2006) e Attaran e Attaran (2007) entendem a prática do CPFR sob duas perspectivas. A primeira, chamada de atividades colaborativas e fundamentais, está relacionada à confiança, cujo foco é a preparação e suporte do relacionamento entre os agentes. A segunda é o lado técnico, relacionada às ferramentas de apoio ao relacionamento baseado na tecnologia da informação e comunicação, as quais procuram uma linguagem comum entre os agentes.

Com base nesses autores, percebe-se que nas atividades relacionadas ao CPFR existe uma tendência de divisão do que é eminentemente tecnológico e o que não é. Para tanto, esta seção discute a importância da tecnologia e da colaboração no CPFR na intenção de classificar o que pode ser entendido como os principais fatores não tecnológicos apontados na literatura estudada. 
Segundo Chang, Lee, Fu, Lin e Hsuech (2007), é aparente que a chave do sucesso do CPFR é a confiança entre os agentes da CS e a tecnologia empregada. Para eles, os membros da CS formam uma organização virtual. Se um membro não atua, o outro pode atuar e diminuir o efeito sobre a demanda.

A Internet tem tornado mais fácil a troca de informações entre os membros da CS e as empresas têm se utilizado desta tendência para alavancar os benefícios obtidos pela troca de informações, melhorando o desempenho operacional e o serviço ao cliente. Numa plataforma colaborativa, com base diária de informação, um fornecedor pode monitorar seus produtos, o nível de estoque, necessidade de reposição etc. em cada ponto de venda (Pramatari \& Miliotis, 2008).

Cassivi (2006) destaca que a colaboração eletrônica torna-se o elemento chave para as empresas buscarem mais eficiência na CS. O autor chama este movimento técnico a favor da colaboração de $e$ colaboration, atribuindo a eles dois processos: o primeiro, que melhora a visibilidade das informações entre os parceiros e o segundo, que oferece suporte às implementações estratégicas da CS. Já Attaran e Attaran (2007) citam o fato de que os produtos tecnológicos que apóiam o CPFR, geralmente, são abertos (padrão e protocolo de sistemas) para facilitar as trocas entre os parceiros.

Para Ghosh e Fedorowicz (2008), há clara diferença entre como clientes e fornecedores vêem o relacionamento. Em alguns casos, o poder do cliente define a natureza do relacionamento e a solução tecnológica que conduzirá a troca de informação no CPFR. A formalização do CPFR, mediante a troca eletrônica de dados, tende a ser dificultada pelo relacionamento por razões técnicas e financeiras. Existem questões de formato requerido para os dados e seus custos podem ser altos para os parceiros. Neste caso, os agentes mais fortes definem as tecnologias na CS que serão utilizados no CPFR. Considerando a importância do relacionamento, este conflito pode não contribuir para os resultados do CPFR.

Fundamentalmente, o CPFR muda o relacionamento transacional (somente compra e venda, por exemplo) para o colaborativo com o cliente. Objetivos comuns devem ser estabelecidos e o fornecedor e o cliente devem concordar em quais informações eles compartilharão. Esta não é uma questão fácil de ser resolvida (Cederlund et al., 2007). Fora isso, como coloca Danese (2007), o nível de colaboração no CPFR depende fundamentalmente da maturidade existente entre os agentes e as unidades que se integram, além de fatores tais como: objetivos do CPFR, características de produtos e do mercado, a estrutura da CS e o estágio em que se encontra o CPFR.

Whipple e Russell (2007) resumem bem a idéia de evolução do CPFR na CS, ao dizerem que à medida que a colaboração evolui, evoluem os processos e esta experiência capacita a construção de outros relacionamentos.

\section{Fatores Não tecnológicos}

A pesquisa literária realizada fundamenta três proposições sobre fatores não tecnológicos que serão investigados nos estudo de casos, conforme salientadas na Figura 1:

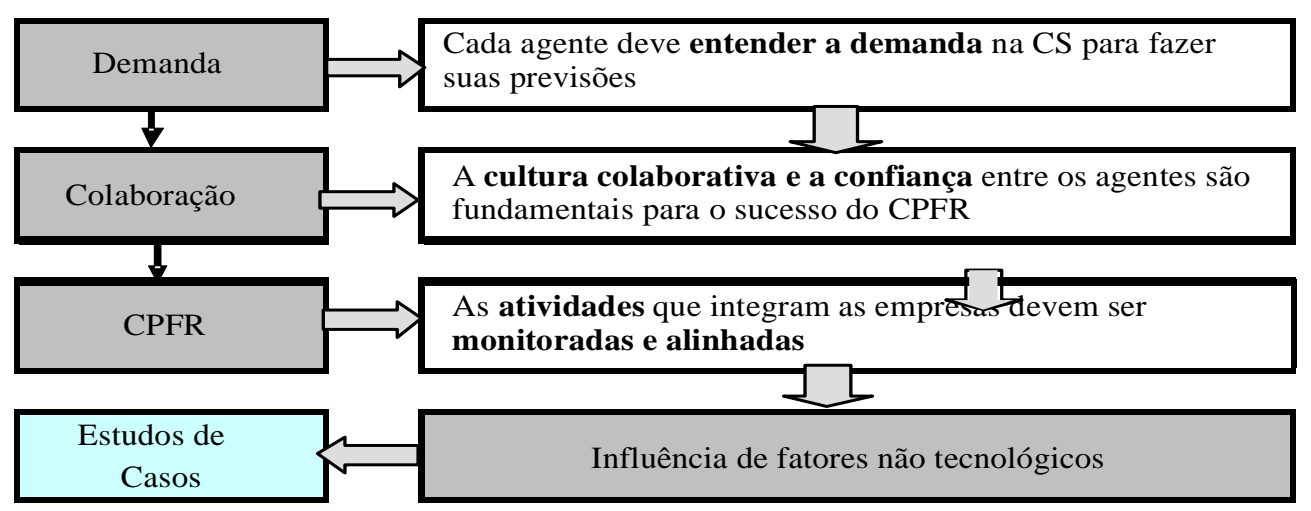

Figura 1. Proposições sobre a Análise Conceitual 


\section{Entender a Demanda}

Ter informações a respeito da demanda é citado pelo VICS (2004) e por diferentes autores como sendo um dos principais objetivos do CPFR. Não é simplesmente obter ou prever um número que será utilizado como base para produzir ou estocar. Como relatam Mentzer e Moon (2004), informações da demanda devem fluir em toda cadeia. Como coordenar este fluxo de informações, classificando o que cada agente deve saber, sempre dentro do menor intervalo de tempo, é o desafio do CPFR. Portanto, as empresas que sabem das informações que precisam de seus parceiros e trabalham essas informações, gerando e corrigindo as previsões, e conseqüentemente seus estoques, fortalecem a cultura de planejamento interno alinhado com a demanda.

Segundo Simatupang, Wright e Sridharan (2004), empresas que atuam nesta linha conhecem a amplitude de sua CS, seu papel e a importância para o negócio em que se inserem.

\section{Cultura Colaborativa e Confiança}

A confiança é apontada em diversos estudos (Danese, 2007; Min et al., 2005; Skjoett-Larsen, Thernoe, \& Andersen, 2003) sobre gestão colaborativa e CPFR como forte componente do relacionamento e do sucesso desse método.

Quanto à troca de informações, sejam estratégicas, de planejamento, ou mesmo troca de dados, as empresas se sentem inseguras, por entenderem que este compartilhamento invade seus negócios. Nesta linha, Attaran e Attaran (2007) discutem os sistemas de informação abertos, facilitando o vínculo entre os agentes. É claro que a empresa, para aceitar esta posição, precisa confiar nos agentes com quem se está relacionando. Já para Ghosh e Fedorowickz (2008), além desses fatores, a confiança tem de estar combinada com um alto nível de comunicação interpessoal.

\section{Monitorar e Alinhar as Atividades que Integram as Empresas: Dados, Indicadores, Decisões etc.}

A demanda deve ser sempre revista no menor intervalo de tempo possível, para gerar previsões mais confiáveis (Forslund \& Jonsson, 2007). Portanto, esta informação tem de estar alinhada e deve ser monitorada pela empresa que coordena a cadeia e/ou o CPFR. Para isso, Barratt (2003) propõe a criação de um comitê com a função de monitorar e alinhar os processos e atividades ao longo da cadeia.

Para Sahay (2003) e Poler et al. (2008), o alinhamento das atividades e processos devem adotar uma perspectiva externa de toda a cadeia, considerando nela as diferenças de relacionamento existentes nos diversos nós da cadeia.

VICS (2004) identifica o alinhamento como um instrumento para estabelecer regras, e estabelece que o monitoramento seja um instrumento de análise, com a responsabilidade de dividir as informações obtidas na cadeia.

O trabalho de monitoramento e alinhamento conduzido pela empresa coordenadora da cadeia não isenta os demais agentes de buscarem as informações de que necessitam, pois, para Chang et al. (2007), a criação de plataformas colaborativas no CPFR permite esta ação.

Segundo Cederlund et al. (2007), no caso Motorola, este trabalho de monitoramento e alinhamento foi um dos pontos fortes do projeto e contribuiu em muito para o sucesso do CPFR. 


\section{Metodologia de PESQUISA}

Desde meados de 2005, os autores deste trabalho veem pesquisando os processos de abastecimento de redes de food-service (alimentação em redes de refeição como restaurantes e fast-food). Em três anos de pesquisas, os autores acompanharam e analisaram um projeto de implementação de CPFR conduzido por um Prestador de Serviços Logísticos [PSL] e por um Distribuidor deste segmento junto a fornecedores, aos pontos de vendas e à rede de fast-food. Assim, a pesquisa foi conduzida na forma de estudo de caso, mais especificamente do estudo de dois casos. A Figura 2 ilustra a estrutura da pesquisa realizada.

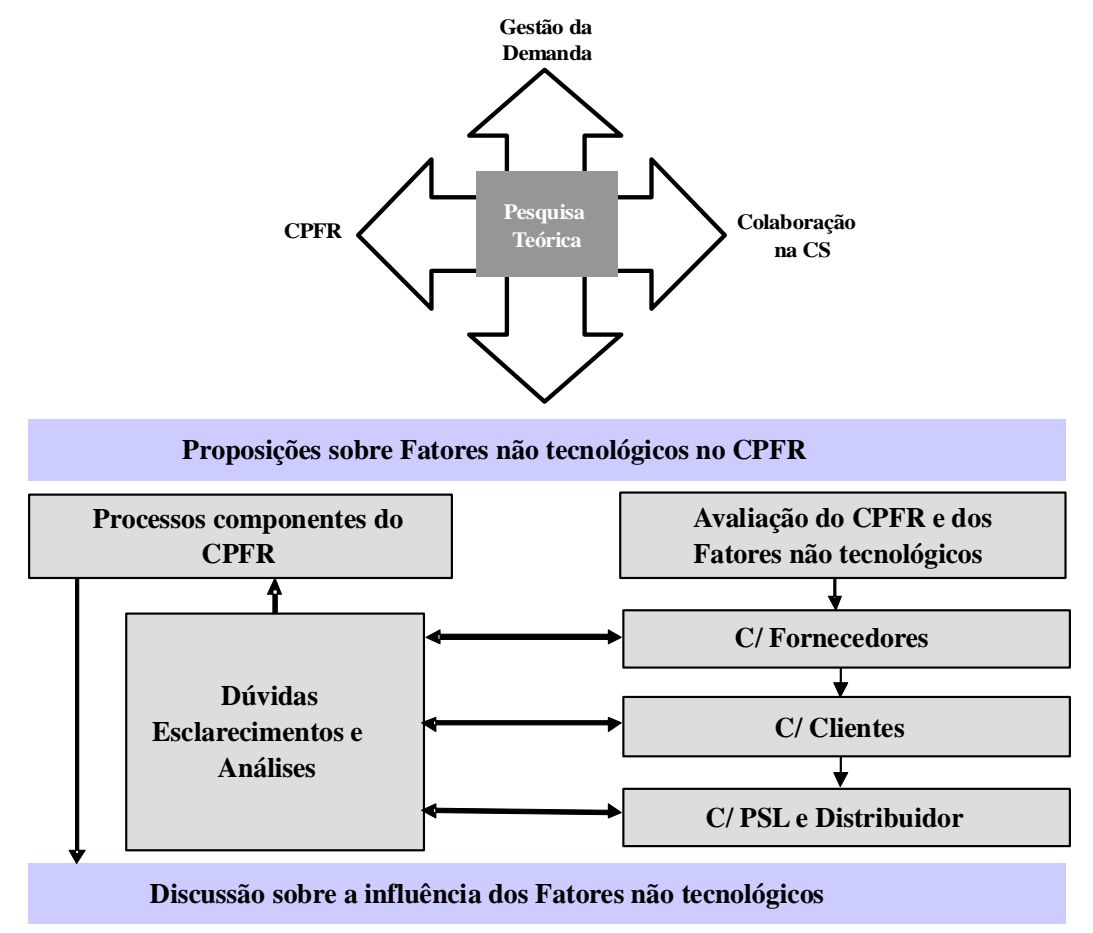

Figura 2. Estrutura Básica da Pesquisa

O estudo teórico deste artigo analisa o tema sob a perspectiva definida pelo VICS (2004), segundo o qual, para entender e melhor controlar a demanda, as empresas na CS necessitam estabelecer relacionamentos colaborativos que servem de base para a utilização do CPFR como método de controle da demanda. Com base nas informações obtidas na teoria, o estudo apresenta as proposições a respeito dos fatores não tecnológicos que influenciam o CPFR, cuja intenção é avaliá-los na prática. Para isso, a pesquisa foi organizada segundo sugestão de Miguel (2007) e Eisenhardt (1989), como segue:

A) Análise da literatura: foi feito um estudo da teoria a respeito de Gestão da Demanda, Gestão Colaborativa na CS e CPFR, com a intenção de delimitar o tema e classificar os fatores não tecnológicos.

B) Planejamento da pesquisa: o interesse dos autores pelas empresas deve-se ao fato de elas serem referências em processos de integração em CS, além da representatividade que possuem na área de food-service. O relacionamento de muitos anos dos autores com as empresas facilitou contatos, coleta de dados e informações.

- Coleta de dados, informações e registro: foi realizada mediante entrevistas (guiadas por questionários semiestruturados) e observações diretas, transcritas pelos autores no decorrer da pesquisa. 
. Filtro de informações: após obter diversas informações e dados, com foco no objetivo da pesquisa (fatores não tecnológicos relacionados ao CPFR), os autores extraíram as informações relevantes e buscaram outras entrevistas com executivos e funcionários das empresas na intenção de obter novos esclarecimentos.

C) Análise do conteúdo e conclusões: buscou-se realizar a análise e o cruzamento dos dados e das informações para esclarecer divergências e dúvidas; retornava-se ao campo, quando necessário, para discussão dos resultados e entendimento das discordâncias junto aos entrevistados. Nesta etapa, a intenção foi evitar conclusões influenciadas pela teoria ou por deduções pré-estabelecidas pelos autores.

No intuito de entender os processos relacionados ao estudo, muitos profissionais foram contatados, observados ou mesmo entrevistados. A Tabela 1 descreve somente aqueles que participaram diretamente das entrevistas.

Tabela 1

Função Exercida pelos Entrevistados e Empresas Pesquisadas

\begin{tabular}{|c|c|c|c|}
\hline Empresa & Entrevistados & Empresa & Entrevistados \\
\hline $\begin{array}{l}\text { Rede de fast- } \\
\text { food }\end{array}$ & $\begin{array}{l}1 \text { gerente de compras } \\
4 \text { gerentes de restaurante } \\
1 \text { gerente regional } \\
1 \text { franqueado } \\
5 \text { fornecedores (gerente da conta) }\end{array}$ & Distribuidor & $\begin{array}{l}1 \text { gerente comercial } \\
1 \text { gerente operacional } \\
1 \text { supervisor de atendimento } \\
1 \text { supervisor de tec. da informação } \\
3 \text { fornecedores (gerente da conta) }\end{array}$ \\
\hline PSL & $\begin{array}{l}1 \text { gerente de atendimento a cliente } \\
1 \text { gerente de tecnologia da informação } \\
1 \text { gerente de operações } \\
1 \text { supervisor de campo }\end{array}$ & Clientes & $\begin{array}{l}4 \text { redes de alimentação } \\
1 \text { gerente responsável de cada } \\
1 \text { gerente do ponto de venda de cada }\end{array}$ \\
\hline
\end{tabular}

\section{DESCRIÇÃO DOS CASOS}

Esta seção traz os dois casos pesquisados, apresentando de forma mais abrangente como as empresas operacionalizaram o CPFR em seus negócios, como as empresas conduziram os processos segundo as quatro atividades propostas pelo VICS (2004) e, por fim, é feita uma análise dos fatores não tecnológicos identificados pelo estudo.

\section{Caso A - Distribuidor}

O distribuidor é uma empresa que atua na venda e distribuição de gêneros alimentícios no mercado de food-service, atendendo a clientes tais como redes de fast-food, cadeias de restaurantes, hotéis e hospitais. Para tais clientes, ele consegue efetuar e operar um processo de distribuição e abastecimento personalizado, seguindo e estabelecendo regras operacionais específicas contratadas por cada cliente.

O modelo operacional de atendimento aos clientes segue um padrão básico, que é sustentado por uma plataforma tecnológica única. Apesar de haver uma base única, as operações por cliente são personalizadas. Nesta relação, o papel de cada agente participante pode ser resumido em:

- Clientes: contratam o serviço da Rede de Distribuição para abastecimento de seu ponto de venda. Definem os padrões operacionais relacionados a serviços contratados com a rede e com os fornecedores 
exclusivos. Estes padrões se referem à frequência de entrega nos pontos de vendas, padrões de qualidade, objetivos e indicadores de produtividade, tais como acerto de pedidos, entregas no horário etc.

No caso de utilização de fornecedores exclusivos, a rede de distribuição trabalha como intermediário, adquirindo e repassando o produto ao cliente. Neste caso, o cliente desenvolve os produtos, define os padrões de qualidade dos produtos, as condições comerciais e trabalha na resolução de conflitos entre os agentes envolvidos.

- Rede de Distribuição: Comercialmente, a rede funciona como grande atacadista voltado ao mercado de food-service, comercializando produtos diversos, comuns ao mercado ou exclusivos de seus clientes. Para cada produto ela estabelece uma margem mercantil, incluindo nela o serviço de atuar mais focado no negócio de cada cliente, respondendo pelo abastecimento dos pontos de venda, pela programação de estoque e pela relação com os fornecedores.

Ela é responsável pela operação de abastecimento dos pontos de venda dos clientes, segundo padrão acordado com cada um. Também, se responsabiliza por efetuar a gestão de estoque dos produtos exclusivos e não exclusivos, armazenar e distribuir, além de atuar no planejamento logístico e fiscal das operações de seus clientes. Além disso, coordena todos os fornecedores no processo de abastecimento, planejando e projetando as necessidades de cada cliente.

Para efetuar essa operação, possui uma infra-estrutura tecnológica sustentada por um grande Enterprise Resource Planning [ERP] e diversos aplicativos comerciais e operacionais. Este sistema permite manter as informações transacionadas entre as empresas e o sistema operacional. Nele está um modelo de CPFR desenvolvido com cada cliente que aceita aplicá-lo na sua cadeia de suprimento.

- Fornecedores: são os responsáveis pelo abastecimento dos produtos exclusivos ou não à rede de distribuição, bem como respondem pela qualidade dos produtos e pela gestão da cadeia de suprimentos no seu sentido montante.

A rede de distribuição mantém com todos os fornecedores uma relação comercial mais independente (para o caso de itens não exclusivos) ou mais dependente (no caso dos itens exclusivos). Isso significa que, no caso dos itens exclusivos, é estabelecida uma margem operacional acordada entre eles. No caso dos não exclusivos, a negociação de preços é definida pelo aceite ou não do preço de venda.

\section{O CPFR Desenvolvido pelo Distribuidor}

Há cerca de três anos a rede de distribuição tem desenhado um processo de CPFR que pode ser implementado para cada tipo de cliente. O cliente pode não utilizá-lo, utilizá-lo parcialmente ou utilizá-lo totalmente. Os clientes que já participam do processo, utilizando parcialmente a ferramenta, têm um portal de relacionamento na internet como meio para acessar, transmitir e obter informações.

Para um adequado entendimento da importância dessa ferramenta, faz-se necessário entender o papel de cada agente no CPFR, como é apresentado a seguir.

- Ponto de venda do cliente: ele pode acessar com transmissão on-line dados sobre as vendas registradas no caixa ou informar a venda posteriormente. A venda é convertida para as unidades de venda segundo o consumo de cada prato utilizado pelo ponto de venda, dependendo do cliente. Também informa o estoque operacional, segundo contagens e acertos necessários pertinentes a cada tipo de negócio. Tem-se um ponto de reposição pré-definido que é referência para gerar uma ordem de pedido. Efetua o pedido segundo sugestão gerada pelo sistema diretamente à rede de distribuição.

. Fornecedores: recebe dois tipos de informação: a do ponto de venda relativa à venda de seu produto (desde que autorizada pelo cliente) e a da rede de distribuição relativo ao nível de estoque atual, programação de reposição e previsão de venda futura, com oito semanas de projeção. Deve disponibilizar no sistema o volume de estoque que possui para atender à rede ou ao cliente 
específico da rede. Seu papel principal é gerenciar as informações para manter a rede de distribuição abastecida, bem como criar a programação necessária a montante de sua cadeia.

- Rede de Distribuição: disponibiliza o portal de relacionamento com cada cliente, ponto de venda e fornecedor, repassando as informações para cada agente envolvido no processo. Dessa forma, cria a sugestão de pedidos de reposição para cada ponto de venda.

Abastece os pontos de venda segundo os pedidos dos clientes, repassando informações e programas de reposição de estoque aos fornecedores. Mantém um banco de dados com histórico de vendas e outras informações solicitadas, conforme acertado com cada cliente.

- Clientes: tem o sistema de informações à disposição para consulta do que acontece em seus pontos de venda e do nível de estoque que possui dos produtos exclusivos na cadeia. Junto com a rede de distribuição, estabelecem critérios e métodos de gestão do processo na cadeia.

\section{Caso B - Rede de Fast-Food}

A rede de fast-food estudada desenvolveu uma relação de compromisso com seus fornecedores, compartilhando missões, objetivos, crenças, e valores. Claramente, essa posição fortaleceu o comportamento colaborativo. Em contrapartida, deu à maioria de seus fornecedores exclusividade no abastecimento dos restaurantes.

Nesta relação, o papel de cada agente participante da cadeia de suprimentos e no CPFR pode ser resumido em:

- Rede de Fast-Food: responsável pela operação dos restaurantes, estabelecimento de promoções e propagandas, seleção de fornecedores, preços e produtos, desenvolvimento de novos produtos, elaboração de planos estratégicos para o negócio, avaliação e padronização dos processos e resolução de conflitos na cadeia.

Como idealizadora do projeto, trabalha no convencimento dos agentes da importância e das possibilidades de ganho para todos. Valida o processo e apóia o PSL em todas as ações de coordenação e implementação. Tem papel fundamental no estimular a relação e a busca de soluções para os diferentes problemas que surgem, bem como para tomar as decisões e definir o caminho, quando surgem impasses. Exerce função atuante no processo de implementação, pois negocia com os fornecedores a participação no processo; trabalha na definição de unidades de venda e codificação dos produtos; define estratégia de volume de estoque com cada fornecedor, repassando essa orientação para o monitoramento do PSL; define os restaurantes e as praças que serão integradas no projeto; orienta os gestores dos restaurantes quanto às práticas e padrões que serão estabelecidos no projeto; valida os impactos de promoção e campanha e permite o acesso aos sistemas dos restaurantes para coleta de dados.

- PSL: responsável pela gestão de compras e estoques, atendimento aos restaurantes, armazenagem, distribuição e transporte, transferências a outros centros de distribuição no país, gestão financeira da cadeia, planejamento logístico, planejamento fiscal, serviço de campo e coordenação das operações de abastecimento na cadeia.

Agente de integração no processo tem no relacionamento com os agentes da cadeia o ponto forte de sua gestão, uma vez que precisa conduzir diversos agentes e diferentes interesses. Ao ser o coordenador das ações e ter força dedicada ao projeto, o PSL assume a responsabilidade de trabalhar para que as ações planejadas se concretizem. Assume o processo de integração entre os sistemas de informação, trabalhando na construção das interfaces dos diversos agentes. Assim, tem como finalidade: integrar todos os agentes, construindo e coordenando os portais ou as interfaces de todas as empresas; manter a coordenação do projeto por meio de gestão exclusiva e dedicada; por ter ampla visão do processo, pode orientar todos os agentes participantes, bem como gerar todas as informações necessárias ao sistema; manter ou mesmo obter a tecnologia necessária para gerar o banco de dados e o sistema de coleta e transmissão de informações. 
- Fornecedores: responsáveis pela manufatura com qualidade assegurada, desenvolvimento de novos produtos e pela gestão a montante da cadeia.

Há três categorias de fornecedores. A primária inclui aqueles fornecedores que atuam praticamente com exclusividade para a rede de fast-food. Aqueles pertencentes à secundária têm outros negócios e clientes, mas o volume é extremamente representativo e interessante como negócio para a empresa. A terceira categoria inclui aqueles que atendem a outros clientes e não fornecem volumes representativos, mas reconhecem que ter a rede como cliente é importante. Desta forma, consegue-se ter a participação de todos, alguns mais focados nos sistemas de integração, outros relativamente livres, mas todos colaborando com o provimento das informações necessárias para alimentar o sistema. Assim, o papel dos fornecedores no processo de CPFR é: acessar todas as informações de estoque, pedidos e previsões no PSL para seus produtos; visualizar a venda real de seus produtos no ponto de venda (consolidada, por região, ou por ponto de venda) e disponibilizar ou transmitir informações sobre seus estoques ao PSL.

\section{Processos Componentes do CPFR nos Casos}

Baseando-se nas quatro atividades propostas pelo VICS (2004), tem-se a seguir, nas Tabelas de 2 a 5, para cada atividade, a descrição dos principais aspectos identificados no caso A e B. Estas atividades e características relacionadas ao CPFR implementado nas empresas estudadas podem ser entendidas como resultados e benefícios obtidos por elas. Este resumo é fruto do trabalho das avaliações, das entrevistas e das observações dos autores obtidas na pesquisa e muitas destas atividades refletem decisões adotadas pelas empresas.

Tabela 2

\section{Atividades Colaborativas dos Casos (Estratégia e Planejamento)}

\begin{tabular}{|c|c|c|c|}
\hline Atividades Colaborativas & Aplic & -se ao & \\
\hline Estratégia e Planejamento & Caso A & Caso B & \\
\hline $\begin{array}{l}\text { Facilitar os processos operacionais e administrativos do ponto de venda reduzindo } \\
\text { tempo de trabalho dos gestores }\end{array}$ & Sim & Sim & * \\
\hline Montar o pedido de compra ideal para os pontos de venda & Sim & Sim & \\
\hline $\begin{array}{l}\text { Automatizar controles de estoque, formação do pedido, e lançamentos fiscais e } \\
\text { contábeis }\end{array}$ & $\underset{\text { (parcial) }}{\operatorname{Sim}}$ & Sim & \\
\hline Obter visibilidade dos estoques na CS & Sim & Sim & * \\
\hline Reduzir o nível de estoque no ponto de venda e na cadeia & Sim & Sim & \\
\hline Criar um grupo executivo com diferentes empresas da CS para decisões estratégicas & Não & Sim & * \\
\hline $\begin{array}{l}\text { Criar um grupo de desenvolvimento e outro de implementação dos conceitos, métodos e } \\
\text { processos }\end{array}$ & Não & Sim & \\
\hline $\begin{array}{l}\text { Definir uma empresa coordenadora para conduzir o projeto, e que também teria o banco } \\
\text { de dados }\end{array}$ & Não & Sim & $*$ \\
\hline Obter informações em tempo real & Não & Sim & \\
\hline Todos os fornecedores de primeiro nível (first tier) estariam no projeto & Não & Sim & $*$ \\
\hline Ter um sistema que se torna um diferencial para o ponto de venda do cliente & Sim & Não & \\
\hline $\begin{array}{l}\text { Criar módulos de integração de dados (exemplo: formação do pedido, controle do } \\
\text { estoque, lançamentos fiscais) }\end{array}$ & $\begin{array}{l}\operatorname{Sim} \\
\text { (parcial) }\end{array}$ & Sim & * \\
\hline Custos relacionados ao desenvolvimento serão diluídos no custo de venda dos produtos & Não & Sim & * \\
\hline
\end{tabular}

Nota. *Tem influência dos fatores não tecnológicos.

RAC, Curitiba, v.14, n. 2, art. 6, pp. 289-309, Mar./Abr. 2010

www.anpad.org.br/rac 
Percebe-se que a estratégia e planejamento entre os dois casos têm na essência o controle da demanda e do estoque, como sugere o CPFR. No caso B, são incorporados componentes que visam dar maior produtividade aos gestores dos pontos de venda e ao mesmo tempo garantir que informações contábeis sejam aproveitadas. A visão estratégica, neste caso, por parte da rede de fast-food, abrange muito mais o seu negócio e toda sua CS do que no caso A, em que o distribuidor adota o CPFR em módulos (o que, segundo o VICS, é possível) como instrumento de venda de serviço.

Nesta etapa, os fatores não tecnológicos têm grande influência, pois o relacionamento entre os agentes é o componente mais forte nesta fase, bem como é fundamental o entendimento do que será conduzido pelo projeto do CPFR. No caso B, a rede de fast-food monta grupos de trabalho como forma de difundir os conceitos e o conhecimento a respeito, dirimindo dúvidas e esclarecendo os objetivos. No caso A, o distribuidor executa este papel, e a decisão de se envolver no projeto é do cliente. De qualquer forma, tanto em um quanto no outro, a confiança tem de estar presente, pelo fato de os agentes estarem atrelados a uma plataforma de dados única.

Tabela 3

\section{Atividades Colaborativas dos Casos (Demanda e Gestão de Abastecimento)}

\begin{tabular}{|c|c|c|c|}
\hline Atividades Colaborativas & Aplic & -se ao & \\
\hline Demanda e Gestão de Abastecimento & Caso A & Caso B & \\
\hline Informações em tempo real a partir de venda no caixa & Não & Sim & * \\
\hline O sistema converte a venda em unidades transacionais na cadeia & Sim & Sim & \\
\hline $\begin{array}{l}\text { O agente coordenador concentra as informações, organiza e projeta as previsões para cada } \\
\text { fornecedor }\end{array}$ & Sim & Sim & $*$ \\
\hline $\begin{array}{l}\text { Cada fornecedor recebe a informação e internamente converte segundo sua } \\
\text { necessidade }\end{array}$ & Sim & Sim & $*$ \\
\hline Novos produtos e promoções utilizam dados históricos de itens semelhantes & Sim & Sim & \\
\hline $\begin{array}{l}\text { Marketing recebe o histórico para novos produtos e promoções e valida as } \\
\text { informações para o sistema }\end{array}$ & Sim & $\operatorname{Sim}$ & \\
\hline $\begin{array}{l}\text { O ponto de venda e os centros de distribuição [CD] tem níveis de estoques } \\
\text { estabelecidos previamente }\end{array}$ & Sim & $\operatorname{Sim}$ & \\
\hline $\begin{array}{l}\text { O fornecedor é quem gerencia seus níveis de estoque, mas tem visibilidade do estoque } \\
\text { no ponto de venda e CD }\end{array}$ & Sim & Sim & \\
\hline A matriz/Rede do ponto de venda pode gerenciar o nível de estoque & Sim & Não & $*$ \\
\hline
\end{tabular}

Nota. *Tem influência dos fatores não tecnológicos.

Considerando que a intenção das empresas é ter visibilidade sobre a demanda e, a partir dela, realizar as projeções e previsões necessárias para a CS, as atividades e pontos de trabalho entre os dois casos são comuns. Em todas as atividades a presença da tecnologia de informação é dominante. Apesar disso, a influência dos fatores não tecnológicos está no fato de não haver entendimento e consenso do que exatamente se quer obter como previsão para que a cadeia produza e estoque. Percebe-se, no caso B, que a rede de fast-food com os grupos de trabalho, divulgação e envolvimento dos objetivos aos agentes, consegue obter mais consenso e entendimento da equipe. No entanto o conceito é discutido, definido e adotado por todos, mesmo que alguns não o entendam. Já no caso A o conceito é construído pelo distribuidor com a participação dos clientes durante a implementação, momento em que ocorrem adaptações e customizações. 
Tabela 4

Atividades Colaborativas dos Casos (Execução)

\begin{tabular}{|c|c|c|c|}
\hline Atividades Colaborativas & Aplic & -se ao & \\
\hline Execução & Caso A & Caso B & \\
\hline $\begin{array}{l}\text { Os trabalhos de implementação foram divididos em ciclos de trabalho (ex: construir a } \\
\text { tela de pedido) e responsáveis definidos }\end{array}$ & Não & Sim & $*$ \\
\hline $\begin{array}{l}\text { Especialistas em TIC são definidos/contratados para atuar na construção do sistema e } \\
\text { na concectividade dos agentes }\end{array}$ & Sim & Sim & \\
\hline Formação de grupos e lojas piloto para testes & $\operatorname{Sim}$ & Sim & $*$ \\
\hline $\begin{array}{l}\text { Todos os agentes estariam conectados via um portal de relacionamento gerenciado pela } \\
\text { empresa coordenadora }\end{array}$ & Sim & Sim & $*$ \\
\hline Todos os agentes têm uma senha de acesso, restringindo-o às informações de interesse & Sim & Sim & \\
\hline $\begin{array}{l}\text { A plataforma de dados da empresa coordenadora se conecta com cada agente e obtém } \\
\text { as informações necessárias }\end{array}$ & $\begin{array}{l}\text { Sim } \\
\text { (parcial) }\end{array}$ & $\operatorname{Sim}$ & $*$ \\
\hline $\begin{array}{l}\text { Necessidade de criar padronização de dados e informações (exemplo: todos devem } \\
\text { utilizar a mesma nomenclatura de produto) }\end{array}$ & Sim & Sim & \\
\hline $\begin{array}{l}\text { Muitos dados precisariam ser abastecidos manualmente pelos agentes (exemplo: } \\
\text { contagens e baixa de estoque por avaria, desperdício) }\end{array}$ & $\operatorname{Sim}$ & $\operatorname{Sim}$ & \\
\hline O ponto de venda e os CDs corrigem informações de estoques & Sim & Sim & \\
\hline $\begin{array}{l}\text { Itens promocionais ou vendas limitadas são gerenciadas pelo sistema, que define } \\
\text { quantidade de abastecimento automaticamente }\end{array}$ & $\begin{array}{l}\operatorname{Sim} \\
(\text { parcial })\end{array}$ & Sim & $*$ \\
\hline O pedido recomendado pelo sistema deve ter o aval do gestor do ponto de venda & $\operatorname{Sim}$ & Sim & \\
\hline
\end{tabular}

Nota. Tem influência dos fatores não tecnológicos.

No que tange à execução, observou-se que as empresas trocam informações e discutem como colocá-las no sistema e como fazer para que o sistema contemple suas necessidades. Neste momento, o papel de técnicos especializados em sistemas contribui para definir as configurações necessárias. Foi observado que a organização por etapas, montando módulos que atendem a cada processo, bem como a definição das prioridades e dependências de um módulo com o outro, facilita a implementação e a construção do CPFR.

Um item chave é a padronização de dados que abastecem o sistema, pois a linguagem tem de ser a mesma em toda a cadeia e nomes de produtos e codificações tem de estar correlacionados. Enfim, o sistema é rígido; se a padronização não for adequadamente considerada, surgirão diversas inconsistências.

Nesta etapa, relacionada à execução, os fatores não tecnológicos se caracterizam pelas ações que necessitam de trabalho em grupo, consenso entre as empresas, aceitação e concessão de informações, permissões de acesso, aceitar regras definidas etc. 
Tabela 5

Atividades Colaborativas dos Casos (Análise e Monitoramento)

\begin{tabular}{|c|c|c|c|}
\hline \multirow{3}{*}{$\begin{array}{l}\text { Atividades Colaborativas } \\
\text { Análise e Monitoramento } \\
\text { Nível do estoque e de confiabilidade do estoque nos pontos de venda e dos CDs }\end{array}$} & \multicolumn{3}{|c|}{ Aplica-se ao } \\
\hline & Caso A & Caso B & \\
\hline & Sim & Sim & * \\
\hline Desperdícios e perdas nos pontos de venda & $\underset{\text { (parcial) }}{\operatorname{Sim}}$ & Sim & * \\
\hline Históricos por ponto de venda, por fornecedor, por produto etc. & Sim & Sim & \\
\hline Performance das entregas e dos fornecedores & Sim & Sim & $*$ \\
\hline Equipe de monitoramento para o pedido recomendado ao ponto de venda & Sim & Sim & \\
\hline Nível de correção dos pedidos recomendados pelo sistema & Sim & Sim & \\
\hline Gestor/analista dedicado ao projeto em cada agente & Não & Sim & * \\
\hline $\begin{array}{l}\text { Reuniões periódicas com o grupo executivo e com representantes dos agentes } \\
\text { participantes }\end{array}$ & Sim & Sim & * \\
\hline Comitê de análise, ligado ao grupo de desenvolvimento, para definir e administrar & Sim & Sim & * \\
\hline Gerar informações relativas ao desempenho da cadeia & Sim & Sim & \\
\hline
\end{tabular}

Nota. Tem influência dos fatores não tecnológicos.

Basicamente, a etapa de análise monitoramento se resume na formação de instrumentos que permitam avaliar, analisar e criar ações para atingir os objetivos traçados no planejamento do CPFR. Portanto, ter informações correlacionadas com a demanda e nível de estoque torna-se imprescindível para as análises.

Os fatores não tecnológicos se caracterizam pela necessidade de que os envolvidos saibam interpretar dados e acessem as informações para correções imediatas. Ter responsáveis em cada unidade para este trabalho mostrou-se, principalmente no caso B, muito importante para avaliar se os processos estavam seguros. Neste caso, a empresa coordenadora do CPFR tem papel fundamental, e o profissional responsável por esta coordenação é quem dita o ritmo aos demais e coordena reuniões para consenso, correções etc.

\section{Análise dos Fatores Não tecnológicos}

Com base nas três proposições, na pesquisa de campo e nas entrevistas com profissionais das empresas, tem-se o que se especifica a seguir.

1) Entender a demanda

Os profissionais demonstram entender a importância de ter a visibilidade da demanda a partir do ponto de venda. Parece haver, contudo, certa confusão quanto aos critérios de como deveriam estabelecer as previsões. Exemplo disto é o fato de muitos não aceitarem, como no exemplo do Caso $\mathrm{B}$, a visualização da previsão por 8 semanas como referência e a validação para abastecimento somente das 2 primeiras semanas. A alegação, de fornecedores no caso, é que alguns produtos exigem um ciclo de produção muito maior e se a demanda neste período sofre variações bruscas, pode sobrar ou faltar produto. 
Muitos agentes (tanto do caso A quanto do B) sugerem o desenho do CPFR, levando-se em conta a projeção da demanda para cada fornecedor, feita pelo coordenador do projeto. Neste ponto, entra um fator não tecnológico relevante, que é como administrar os riscos do negócio. Sem o CPFR, cada um assume um número de previsão; mas, quando trabalham em conjunto no CPFR, é como se entendessem que os riscos devessem ser repassados a quem gerou a informação.

Entretanto, percebe-se que os agentes das cadeias compreendem a dificuldade de se obter amplo consenso entre todos; por isso, quando o coordenador ou as empresas responsáveis impõem uma regra, desde que explicado seu mecanismo, aceitá-la é o melhor para o CPFR. No caso, percebem que ter as informações geradas pelo CPFR é ter muito mais do que possuem sem ele.

Gestores dos pontos de venda não têm grande preocupação com a geração das previsões, pois acreditam que o mais importante é ter o pedido de compra bem feito. Nesta questão, demonstram haver receio em acatar exatamente o que o sistema propõe e, geralmente, acrescentam uma margem de segurança sobre os números sugeridos para os itens básicos. Isto demonstra não haver entendimento do reflexo que isto causa na cadeia e o custo que isto significa.

\section{2) Cultura Colaborativa e confiança}

É consenso que a união das empresas em torno de um projeto como o CPFR, como no caso B, favorece a colaboração e todos demonstram interesse em colaborar, pois sabem que a intenção é haver favorecimento para a rede. Se conseguirem ter números mais confiáveis, eles também se beneficiam com isso. Tanto a rede de fast-food quanto o PSL têm a mesma posição: mesmo que não haja divisão de ganhos, a redução de estoque e a confiabilidade que o sistema gera trazem benefícios a todos.

No caso A, o distribuidor tem todo o CPFR sob seu controle e os clientes sabem que isto é um produto de venda. Com isso, a cultura colaborativa mistura-se com interesse comercial e o beneficio que se tem ao aceitar o serviço. Esta cultura vai aparecer no momento da implantação e da execução. Os gestores comentam que a construção dos módulos, desenhando-se cada particularidade de seus negócios, se dá em bom nível e conseguem consenso na maioria das questões.

Um fato evidente é que todos dizem ter confiança no distribuidor, na rede de fast-food, no coordenador dos processos e no método do CPFR. Não acreditam haver manipulação das informações e confiam na segurança da rede. Apesar disso, no caso do distribuidor, os clientes julgam não ser necessário coletar dados do caixa, como se isso fosse uma invasão desnecessária. Neste caso, utilizam o input manual como alternativa, porém contestada pelos profissionais da rede de distribuição. Apesar deste conflito, os clientes sentem-se seguros com o abastecimento executado pela rede de distribuição, pois o índice de ruptura de estoque é próximo de zero (0,5\%).

Os gestores que fazem parte do comitê executivo da rede de fast-food julgam serem estes dois fatores importantes; mas é consenso, quando entram em processo como esse, que haverá imposições para que aceitem as regras e iniciem o processo. Apesar disso, quando as empresas começam a trabalhar de forma integrada, acreditam que a relação melhora e algumas resistências são rompidas.

3) Monitorar e alinhar as atividades que integram as empresas (dados, indicadores, decisões etc.)

No caso A, o distribuidor assume o monitoramento e efetua todos os controles, ajustes de dados e informações, e coordena reuniões periódicas com cada cliente. Neste caso, tanto o distribuidor quanto os clientes consideram importante esta iniciativa.

Todos valorizam as projeções feitas para cada produto e concordam que comparar os dados e informações sobre estoque com a os níveis estabelecidos é importante. Neste aspecto, consideram o papel do coordenador e a estrutura que confirma os dados muito importantes. Alguns destacam que dificilmente conseguiriam as informações com a estrutura de TI que possuem.

Para os gestores dos pontos de venda, a informação sobre perdas e desperdícios representa a exposição de falhas de sua gestão. Criticam as formulações adotadas para o cálculo do consumo e 
consideram este tema pouco abordado pelos comitês. Apesar disto, tanto eles quanto os demais acreditam que os comitês são fundamentais para ajustes e entendimentos.

Existem manifestações de alguns entrevistados de que faltam informações nas telas de desempenho ou de previsões. Alguns demonstram confundir o que seria monitoramento do sistema e das informações necessárias à CS, com necessidades que possuem. Por exemplo, fornecedores de segmentos concorrentes gostariam de visualizar a demanda total de itens que poderiam fornecer também, mas não fornecem. Isto aparece como crítica à rede de fast-food e ao distribuidor por alguns fornecedores.

\section{Considerações sobre a Pesquisa de Campo}

Para ajudar a responder à questão sobre a influência dos fatores não tecnológicos no CPFR, bem como destacar aspectos relevantes para projetos desta natureza, os autores resumem neste capítulo as principais considerações levantadas na pesquisa.

A proposta do distribuidor, no caso A, em oferecer a seus clientes um pacote de ferramentas tecnológicas, tem a intenção de fortalecer os serviços e ter um diferencial comercial. Seus representantes entendem desta forma e não atribuem muita importância aos fatores não tecnológicos apresentados por este estudo. Consideram importante seu entendimento, mas não relevante para a implementação e condução das operações do CPFR junto aos clientes. Avaliam que, quando iniciam a implementação, de fato, aparecem as questões relacionadas aos fatores não tecnológicos, como a falta de entendimento de como se compõe a previsão da demanda, percebem dificuldades no relacionamento com alguns gestores, principalmente os responsáveis pelo ponto de venda, por resistirem em adotar certos procedimentos; mas, quando começam a operar e recebem as primeiras informações e cobranças, eles reagem e começam a participar e se envolver com os resultados.

Ainda assim, diversos entrevistados afirmam o seguinte: com o monitoramento das operações é possível alinhar os participantes em torno dos objetivos que foram definidos pelos responsáveis das empresas; e os fatores demanda e relacionamento são resolvidos com o decorrer das operações. Vale observar que a confiança entre os agentes é menor no início dos trabalhos de implementação do CPFR; aumenta à medida que desenvolvem as operações conjuntamente. No início, dizem ter a impressão de que alguém quer levar vantagem, como no caso A, em que os clientes temem haver interesse do distribuidor em empurrar mais produtos do que realmente precisam.

No caso B, os profissionais da rede de fast-food e do PSL atribuem ao bom relacionamento e à forte cultura que existe na cadeia o sucesso da implementação e dos resultados obtidos. Apresentam falta de produto no ponto de venda próximo de zero, ou seja, o ponto de venda recebe $99,7 \%$ dos itens pedidos, já o acerto do pedido final (comparação entre o pedido sugerido pelo sistema e o modificado pelo gestor) fica em torno de $70 \%$. A redução de estoque em dias caiu 0,5 dia no ponto de venda, e próximo de 2 dias nos Centros de Distribuição, o que percentualmente é cerca de $20 \%$ e $30 \%$ respectivamente. Também, consideram o monitoramento e as reuniões dos comitês fundamentais para corrigir processos e alinhar os participantes. Apesar disto, os gestores dos pontos de venda, mesmo recebendo a informação de que alguns itens estavam com o nível de estoque acima (na média um dia a mais do que efetivamente precisavam, principalmente em carnes e pães), não reagiam para reduzi-lo. Isto pode representar certa insegurança com o sistema, ou uma forma de administrarem o risco.

No caso dos clientes do distribuidor, é aparente certa desconfiança quanto às informações repassadas, tanto que as cinco empresas analisadas não forneciam informação em tempo real, principalmente a venda direta do caixa, que primeiro era consolidada por eles para depois ser repassada ao sistema. Apesar disso, os entrevistados não manifestaram haver problemas no repasse das informações, sinal de que o monitoramento feito pelo distribuidor é eficaz.

Todos os entrevistados, tanto do caso A quanto do B, enfatizaram a importância de existir um sistema de dados robusto, capaz de coletar e processar as informações, de estar aberto e operando 24 horas por dia. Não citam receios de o sistema não funcionar ou parar. Demonstram respeitar a 
coordenação efetuada pelo PSL no caso B da rede fast-food e seguem as regras impostas pelo distribuidor no caso A.

É evidente, tanto no caso A quanto no B, que o relacionamento pautado por uma disposição colaborativa entre as empresas ajuda o CPFR; no entanto isto não é determinante na implementação e condução dos trabalhos. Não foi observado pelos autores da pesquisa se havia conflito entre as empresas, ou mesmo se os conflitos comerciais afetaram a utilização do CPFR. Nos casos estudados, percebe-se que a utilização da ferramenta é tida como ação de caráter operacional, em que os possíveis conflitos comerciais pouco afetavam a condução dos trabalhos.

Outro aspecto relevante é que, no caso A, o investimento para construção e manutenção da ferramenta é unilateral, ficando a cargo apenas do distribuidor. Já no caso B, o investimento é compartilhado no preço dos produtos. Isto pode estar relacionado ao tipo de negócio em que as empresas se inserem. Na rede de distribuição, a ferramenta pode ser utilizada como instrumento de venda de produtos e serviços. Já na rede de fast-food, o interesse é compartilhado com o PSL, para que a operação se ajuste à demanda, evitando rupturas e excessos de estoques, e assim prejuízos para as vendas e o negócio dos dois. Esta questão também é relevante no caso A, mas ganha conotação de caráter mais comercial no caso B.

A percepção de que haja maior entendimento dos fatores não tecnológicos entre as empresas envolvidas no caso A e B é muito mais forte na rede de distribuição, na rede de fast-food e no PSL, do que em fornecedores e clientes.

\section{CONCLUSÕES E CONSIDERAÇÕES FINAIS}

O CPFR, fundamentalmente, se apóia na tecnologia de informação e comunicação. Entretanto, como enfatiza o guia publicado pelo VICS (2004) e evidenciado por esta pesquisa, a gestão das variáveis não tecnológicas que cercam este processo tem também muita relevância, uma vez que, sem orientação, sem planejamento e monitoramento, o CPFR pode não proporcionar os resultados esperados. Portanto este artigo confirma a relevância dos fatores não tecnológicos, ao apresentar e discutir os casos estudados, a partir de pressupostos não tecnológicos.

Também, a pesquisa apresenta como o CPFR foi utilizado para beneficiar comercialmente os negócios (exposto no caso A) e favorecer ou melhorar os serviços (apresentado no caso B). Além disso, a narrativa dos casos e a classificação dos processos componentes do CPFR ajudam a entender etapas importantes que exigem atenção das empresas em projetos similares.

A pesquisa ressalta que nem todos os agentes necessitam ter o conhecimento nem todas as informações a respeito da cadeia; mas esses agentes devem desempenhar corretamente o papel que lhes foi atribuído. Portanto, a partir da análise desses dois casos, entende-se que o relacionamento consolidado entre os agentes da cadeia favorece os processos e a gestão do CPFR, assim como se pôde evidenciar que rotinas bem estabelecidas, monitoradas e com responsabilidades bem definidas contribuem para a confiabilidade do processo.

Ficou evidente na pesquisa com os profissionais das empresas que a intenção e a coordenação das empresas líderes do CPFR são mais relevantes do que a cultura colaborativa que o CPFR pressupõe precisar, como abordado pelo VICS e outros autores (Cassivi, 2006; Min et al., 2005).

Ficou claro também que a divisão de ganhos, abordada por alguns autores na gestão colaborativa (Simatupang et al., 2004; Wilding \& Humphries, 2006), não foi evidenciada como prática nos dois casos. E isso não se apresentou como problema dentro da gestão colaborativa e confiança na análise dos fatores não tecnológicos junto aos entrevistados. Parece ter sido entendido pelos agentes que os 
coordenadores procuram melhorar seus resultados; e o ganho para os demais elos na cadeia deve aparecer com a melhora dos níveis de estoque ou com a redução nas rupturas de venda.

Os gestores da empresa coordenadora (caso B) e do distribuidor (no caso A), na função de monitorar e alinhar as empresas no CPFR, devem levar em conta as informações e interesses para a cadeia como um todo, não podendo privilegiar um ou outro com informações dedicadas. Esta consideração foi feita por alguns entrevistados que gostariam de receber informações dedicadas, construídas para eles, ao julgarem ser esta a função do grupo coordenador nas atividades de monitoramento e alinhamento.

Um aspecto relevante da pesquisa é que nos dois casos se percebe haver uma imposição do projeto e dos processos pelos coordenadores e líderes do CPFR. A ressalva está apenas na forma de como são conduzidos os trabalhos, se mais ou menos participativos. Isto permite o entendimento de que a cultura colaborativa e a confiança não se apresentam como fator imprescindível ao CPFR. Apesar desta consideração, o sistema e a condução dos trabalhos favorecem a cultura colaborativa e a confiança.

Como colocado pelo VICS (2004), o CPFR pode ser implementado em partes. Isso ficou evidenciado nos dois casos em que o distribuidor atua com essa formatação e a rede de fast-food criou etapas para avançar nos processos. Independentemente dos módulos ou partes que os agentes utilizam para implementação ou condução do CPFR, os fatores não tecnológicos sempre estarão presentes.

Pode-se então destacar como fatores não tecnológicos importantes no desenvolvimento, implementação e gestão do CPFR: (1) o entendimento da demanda na cadeia; (2) o desenvolvimento de uma cultura colaborativa e de confiança mútua entre os agentes da cadeia; e (3) o monitoramento e alinhamento das atividades/operações na cadeia de suprimentos. O estudo apresentou e analisou essas três proposições a respeito dos fatores não tecnológicos no CPFR, abordadas nas entrevistas e discutidas neste trabalho. Entretanto existe a possibilidade de melhor detalhá-las, classificando-as em subgrupos, como foi percebido no caso da administração dos riscos; ampliam-se, assim as possibilidades para novos estudos nessa linha. Essa possibilidade restringiria melhor as variáveis dos fatores não tecnológicos e permitiria dilatar a visão a respeito destes fatores no CPFR.

\section{Artigo recebido em 22.07.2008. Aprovado em 16.04.2009.}

\section{REFERÊNCIAS BIBLIOGRÁFICAS}

Attaran, M., \& Attaran, S. (2007). Collaborative supply chain management: the most promising practice for building efficient and sustainable supply chains. Business Process Management Journal, 13(3), 390-404.

Barratt, M. (2003). Positioning the role of collaborative planning in grocery supply chains. The International Journal of Logistics Management, 14(2), 53-66.

Barratt, M. (2004). Understanding the meaning of collaboration in the supply chain. Supply Chain Management: An International Journal, 9(1), 30-42.

Bowersox, D. J., Closs, D. J., \& Stank, T. P. (2003). How to master cross-enterprise collaboration. Supply Chain Management Review, 7(4), 18-28.

Caridi, M., Cigolini, R., \& Demarco, D. (2006). Linking autonomous agents to CPFR to improve SCM. Journal of Enterprise Information Management, 19(5), 465-482.

Cassivi, L. (2006). Collaboration planning in a supply chain. Supply Chain Management: An International Journal, 11(3), 249-258. 
Cederlund, J. P., Kohli, R., Sherer, S. A., \& Yao, Y. (2007). How Motorola put CPFR into action. Supply Chain Management Review, 10(7), 28-35. Recuperado em 23 novembro, 2008, de http://www.scmr.com/article/ca6492750.html

Chang, T., Lee, W., Fu, H., Lin, Y., \& Hsuech, H. (2007). A study of an augmented CPFR model for the 3C retail industry. Supply Chain Management: An International Journal, 12(3), 200-209.

Cox, A. (2004b). Business relationship alignment: on the commensurability of value capture and mutuality in buyer and supplier exchange. Supply Chain Management: An International Journal, 9(5), 410-420.

Cox, A. (2004a). The art of possible: Relationship management in power regimes and supply chains. Supply Chain Management: An International Journal, 9(5), 346-356.

Danese, P. (2007). Designing CPFR collaborations: insights from seven case studies. International Journal of Operations \& Production Management, 27(2) 181-204.

Eisenhardt, K. M. (1989) Building theories from case study research. Academy of Management Review, 14(4), 532-550.

Fliedner, G. (2003). CPFR: an emerging supply chain tool. Industrial Management \& Data Systems, 103(1), 14-21.

Forslund, H., \& Jonsson, P. (2007). The impact of forecast information quality on supply chain performance. International Journal of Operation \& Production Management, 27(1), 90-107.

Ghosh, A., \& Fedorowickz, J. (2008). The role of trust in supply chain governance. Business Process Management Journal, 14(4), 453-470.

Golic, S. L., \& Mentzer, J. T. (2006). An empirical examination of relationship magnitude. Journal of Business Logistics, 27(1), 81-108.

Kent, J. L., \& Mentzer, J. T. (2003). The effect of investment inter-organizational information technology in a retail supply chain. Journal of Business Logistics, 24(2), 155-175.

Mentzer, J. T., \& Moon, M. A. (2004). Understanding demand. Supply Chain Management Review, $8(4), 38-45$.

Miguel, P. A. C. (2007). Estudo de caso na engenharia de produção: estruturação e recomendações para sua condução. Produção, 12(1), 216-229.

Min, S., Roath, A. S., Daugherty, P. J., Genchev, S. E., Chen, H., \& Arndt, A. D. (2005). Supply chain collaboration: what's happening? The International Journal of Logistics Management, 16(2), 237-256.

Poler, R., Hernandez, J. E., Mula, J., \& Lario, F. C. (2008). Collaborative forecasting in networked manufacturing enterprises. Journal of Manufacturing Technology Management, 19(4), 514-528.

Porier, C. C., \& Quinn, F. J. (2006). Survey says: solid gains (The third annual global survey of supply chain progress). Supply Chain management Review, 10(1), 34-41.

Pramatari, K., \& Miliotis, P. (2008). The impact of collaborative store ordering on shelf availability. Supply Chain Management: An International Journal, 13(1), 49-61.

Sahay, B. S. (2003). Supply chain collaboration: the key to value creation. Work Study, 52(1), 76-83.

Sari, K. (2008). Inventory inaccuracy and performance of collaborative supply chain practices. Industrial Management \& Data Systems, 108(4), 495-509. 
Simatupang, T. M., Wright, A. C., \& Sridharan, R. (2002). The collaborative supply chain. International Journal of Logistics Management, 13(1), 15-30.

Simatupang, T. M., Wright, A. C., \& Sridharan, R. (2004). Applying the theory of constraints to supply chain collaboration. Supply Chain Management: An International Journal, 9(1), 57-70.

Skjoett-Larsen, T., Thernoe, C., \& Andersen, C. (2003). Supply chain collaboration: theoretical perspectives and empirical evidence. International Journal of Physical Distribution \& Logistics Management, 33(6), 531-549.

Smith, L. (2006). West marine: a CPFR success story. Supply Chain Management Review, 3(2), 28-35. Recuperado em 23 novembro, 2008, de http:// www.scmr.com/article/ca6317964.html

Thron, T., Nagy, G., \& Wassan, N. (2006). The impact of various levels of collaborative engagement on global and individual supply chain performance. International Journal of Physical Distribution \& Logistics Management, 36(8), 596-620.

Voluntary Interindustry Commerce Standards. (2004). CPFR - Collaborative Planning, Forecasting and Replenishment - Guidelines 2004. Recuperado em 23 novembro, 2008, de http://vics.org/docs/committees/cpfr/cpfr_overview_us-A4.pdf

Whipple, J. M., \& Russel, D. (2007). Building supply chain collaboration: a typology of collaborative approaches. The International Journal of Logistics Management, 18(2), 174-196.

Wilding, R., \& Humphries, A. S. (2006). Understanding collaborative supply chain relationships through the application of the Williamson organizational failure framework. International Journal of Physical Distribution \& Logistics Management, 36(4), 309-329. 